Article

\title{
How Far Has China's Urbanization Gone?
}

\author{
Yiping Xiao ${ }^{1,2,3, *}$, Yan Song ${ }^{2}$ and Xiaodong $\mathrm{Wu}^{4,5,6}$ \\ Center for Economic Development Research, Wuhan University, Wuhan 430072, China \\ 2 Department of City and Regional Planning, The University of North Carolina at Chapel Hill, \\ Chapel Hill, NC 27599, USA; ys@email.unc.edu \\ 3 Population, Resources and Environment Economics Research Center, Wuhan University, \\ Wuhan 430072, China \\ 4 Department of Economics, The University of North Carolina at Chapel Hill, Chapel Hill, NC 27599, USA; \\ wuxd4j@gmail.com \\ 5 American Public University Systems, Charles Town, WV 25414, USA \\ 6 University of Phoenix, Phoenix, AZ 85040, USA \\ * Correspondence: xapple915@163.com; Tel.: +86-131-0067-7471
}

Received: 3 July 2018; Accepted: 16 August 2018; Published: 20 August 2018

check for updates

\begin{abstract}
China's rapid urbanization has attracted wide international attention. However, it may not be sustainable. In order to assess it objectively and put forward recommendations for future development, this paper first develops a four-dimensional Urbanization Quality Index using weights calculated by the Deviation Maximization Method for a comprehensive assessment and then reveals the spatial association of China's urbanization by Exploratory Spatial Data Analysis. The study leads to three major findings. First, the urbanization quality in China has gradually increased over time, but there have been significant differences between regions. Second, the four aspects of urbanization quality have shown the following trends: (i) the quality of urban development has steadily increased; (ii) the sustainability of urban development has shown a downward trend in recent years; (iii) the efficiency of urbanization improved before 2006 but then declined slightly due to capital, land use, and resource efficiency constraints; (IV) the urban-rural integration deteriorated in the early years but then improved over time. Third, although the urbanization quality has a significantly positive global spatial autocorrelation, the local spatial autocorrelation varies between eastern and western regions. Based on these findings, this paper concludes with policy recommendations for improving urbanization quality and its sustainability in China.
\end{abstract}

Keywords: urbanization quality; urbanization quality index; sustainable urbanization; assessment; deviation maximization method; spatial autocorrelation; China

\section{Introduction}

After 200 years of development, urbanization is undergoing an important transformation-its center of gravity has shifted from developed countries to the developing world [1]. In particular, China's rapid urbanization has attracted international attention [2]. The level of urbanization increased from $17.92 \%$ in 1978 to $58.52 \%$ in 2017 [3], which has surpassed the world average of $54.74 \%$ [4]. If the current trend holds, China's urban population is estimated to exceed 1 billion people in the next two decades, which is presaged to cause a surge in China's consuming capacity [5]. China's urbanization, which was identified by Joseph E. Stiglitz, as one of the two main forces shaping the world in the 21st century, has had a profound impact on China's economy as well as the world economy [6]. However, China's urbanization has also faced several distinctive problems in comparison with other countries.

Before going into details of these China-specific issues, it is very helpful to examine the contemporary debate on "urbanization" and how it is defined. Due to the complexity of the 
urbanization process, the focus of urbanization varies in different fields of study. From a demographic point of view, urbanization refers to the gradual increase in the proportion of people living in urban areas [7]. From a geographical point of view, urbanization emphasizes the transformation of non-urban areas into urban areas and the resulting spatial transfer of population and economic activities [8]. From an economic point of view, urbanization is defined as the upgrading of industrial and infrastructure, in which agricultural activities are gradually transformed into non-agricultural activities [9]. In short, although urbanization does not have a standard definition, it has been commonly recognized as a dynamic, multi-dimensional socio-spatial process, involving economic development, social transformation, cultural dissemination, ecological conservation, geographical layout, urban governance, and a series of related issues in addition to the migration from rural to urban areas $[10,11]$.

Due to the complexity, some scholars suggested that "urbanization quality" should be used to replace "urbanization level" in assessing urbanization [12-15]. This is because, in terms of the urbanization process, quality refers to the development of urban functionality and the extent to which it can meet the current and future needs of its citizens [16]. In consideration of this, many studies have emphasized the fairness, efficiency, and sustainability of urban development and put forward the concepts of "harmonious city," "eco-city," "sustainable city," "green city," "compact city," and "smart city" [17-21]; all these concepts are essentially similar to the urbanization quality mentioned above.

Based on the understanding of urbanization quality, the problems in the process of China's urbanization are obvious. First of all, the unique Household Registration System has caused "incomplete urbanization" [22]. When the Chinese Communist Party came into power in 1949, it established a Household Registration System to control people's movement between rural and urban areas. Individuals were categorized as "rural residents" or "urban residents" based on their birthplace, and their children inherit the parents' status no matter where they are born or where they live [23]. With the rapid development of cities, hundreds of millions of rural residents come to work and live in the city as migrant workers, but they are barred from acquiring an "urban resident" registration, which means they cannot enjoy the same welfare benefits as registered urban residents in terms of medical treatment, public education, and social security. However, according to the regulations, migrant workers who work and live in cities for more than six months will be counted as "urban residents" in the calculation of the level of urbanization [3]. This inconsistency leads to "incomplete urbanization." In 2017, only about 589 million out of 813 million Chinese urban dwellers have registered as urban residents, that is, the complete level of urbanization is $42.35 \%$ [3].

Moreover, China's urbanization significantly deviates from the coordinated mutual development of urban and rural areas due to the attention and importance given to urban development. Because of this uneven development, the income gap between urban and rural households has continued to expand and caused a series of unhealthy growth issues: (i) urban disease: excessive concentration and population growth in metropolises, resulting in traffic congestion and environmental degradation; (ii) rural disease: a shortage of produce funds and public services due to the capital restrictions, a high proportion of weak and old labor in rural areas, and a large number of young rural laborers flown to cities; (iii) social disease: the expanding income gap between urban and rural areas leading to more intensified social conflicts, and higher occurrence of mass incidents and crimes [24].

In addition, the local government's "land financing" leads to urban overexpansion. In developed countries, due to the high population density, limited living space, and heavy traffic in cities, people tend to live in the suburbs. Urban expansion is a market-driven outcome [25]. By contrast, China's urban expansion is mainly led and monopolized by the local government. To meet the expenditure and achieve GDP growth goals, land sale has been a ready and single solution. Land revenue represents a major source of local revenue, accounting for $60-80 \%$ of the local government's total revenue [26]. However, too much land for sale has diverted urban development from its planning, resulting in overexpansion and waste of resources. More seriously, the loss of a large amount of high-quality arable land may lead to risks associated with food security and the environment. 
Furthermore, China's urbanization has ignored ecological conservation and sustainable use of nonrenewable natural resources because of the strong emphasis placed on economic development, as measured purely by GDP. Such an overemphasis on economic development has resulted in repeated construction, overcapacity, waste of resources, and serious environmental pollution [11].

The root of the above problems is the neglect of the complexity of the urbanization process. In China, the government pays too much attention to the increase of the proportion of urban population, but ignores the quality of urbanization. As we discussed above, urbanization is a multi-dimensional concept, so to make a reasonable judgement an Urbanization Quality Index (UQI) should be established. Although much effort is being spent examining China's urbanization, it is clear that there is no shortage of controversy and the quantitative assessment is difficult [27]. There are two critical problems to be solved: one is designing an appropriate index system; the other is identifying a perspective on the study of dynamic evolution.

In a provincial panel data context, the purpose of this paper is to design a comprehensive UQI for a better understanding of how far China's urbanization has gone and to put forward policy implications. The rest of the paper is organized as follows. The next section will shed light on how to build a comprehensive index of urbanization by summarizing the existing literature. Next, the paper will introduce the research data and methods. This will be followed by a discussion of evolutionary trends and spatial characteristics of China's urbanization. Finally, the paper will conclude with a highlight of major findings and some policy implications.

\section{A Comprehensive Urbanization Quality Index}

The idea to design a comprehensive index to assess the quality of urbanization was initially proposed by Japanese scholars Hattori, Kagaya, and Inanaga in 1960. They specialized in urbanization studies and designed a five-dimensional index covering city size, location, economic activities, employment, and population growth to assess urban development [28].

Since then, with the concept of "sustainable development" being introduced, sustainable urbanization was promoted as a solution to existing urban problems, because it emphasizes continuous improvement to the quality of urban life in various areas such as ecology, culture, politics, infrastructure, and social and economic development. Moreover, such improvements should not increase the burden of future generations [19]. The United Nations Habitat then developed the City Development Index and the Urban Indicators Guidelines. The former consists of five sub-indices: city product, infrastructure, waste, health, and education [29]. The latter includes shelter, social development and eradication of poverty, environmental management, economic development, and governance [30].

Moreover, "quality of life" is another significant index of urbanization quality. The World Summit for Social Development at Copenhagen in 1995 pointed out that the ultimate goal of urban development is to improve the quality of life [31]. Therefore, many scholars began to study the quality of life in urban areas [32,33]. The European Union (EU) has released a survey called "Perception of Quality of Life in European Cities" every three years since 2004. The survey monitors and compares the quality of local life from four aspects by 22 indicators, including public transport, health care services, employment opportunity, air quality, etc. [34].

In addition, other researchers have conducted broader studies from a different point of view. Yanitsky, Caprotti, and Childers et al. focused on ecological cities and pointed out that an eco-city is built on the foundation of ecology principles, where there is balanced social, economic, and environmental development; highly efficient use of resources, energy, and information; and a sustainable, ecologically virtuous circle of human settlement $[18,35,36]$. UN-Habitat and Pan engaged in research into harmonious cities and stated that a harmonious city should satisfy three aspects: spatial harmony, social harmony, and environmental harmony, which means a balance of appropriate economic and population growth; equality and justice in health care, education, and employment; and the reasonable consumption of natural resources during urban development $[17,37]$. Artmann et al. conducted research into smart-compact-green cities and 
considered that the indicator-based smart-compact-green city framework can be characterized through smart environment, smart multi-functionality, smart government, and smart governance [20]. Gradinaru et al. built a four-dimensional framework including efficient built-up development, conservation of agricultural land, landscape preservation, and human perception to assess the efficiency of the planning process and urbanization patterns [38].

Although extensive research has been devoted to the assessment of urbanization quality and we are far from reaching a consensus about UQI, there are some interesting findings: (I) urbanization quality involves the overall coordinated development of the internal system of a city. It includes the economic, social, and ecological development of the city as well as the city's infrastructure and living conditions $[18,19,28-30,34-37]$; (II) The urbanization quality emphasizes the sustainability of urban development. It not only pays attention to the current conditions of cities, but also introduces the concepts of "green," "ecological," and "harmonious," emphasizing the economic, social, and environmental sustainability in the process of urbanization [17-20,29,30,35-37]; (III) The urbanization quality stresses the efficiency of urbanization. Especially from the perspective of planning, scholars are very concerned about whether the urban expansion is under control and whether the urban construction meets the expectations of planning [20,38].

Therefore, this paper will fully consider the above three aspects in designing the UQI. However, as we discussed earlier, China's urbanization is distinctive. The Household Registration System has led to urban-rural segmentation; meanwhile, the government has implemented policies that give excessive importance to urban development, resulting in an imbalance between urban and rural development. The ultimate goal of urbanization is to achieve urban-rural integrated development [12], thus the UQI should also consider the balance of rural and urban development.

So far, we have constructed a four-dimensional framework of UQI. First is the quality of urban development, which is the core content of urbanization. The purpose of urbanization is to promote economic and social development and improve people's living standard [14]. Therefore, the quality of urban development should include the economic, social, and ecological development of the city as well as the city's infrastructure and living standards. Second is the sustainability of urban development, which reflects the potential of urban development. It measures whether the city's economic development is benefited, whether the social burden is too heavy, and whether environmental protection is implemented. Third is the efficiency of urbanization. If urbanization is viewed as a process of input and output, the input includes capital, labor, land, energy and other natural resources and the output is the quality of urbanization [39]. The literature [20,38] may only consider the input of land and capital from the urban planning angle, but other inputs are equally important. Fourth is the urban-rural integration. The ultimate goal of urbanization is to achieve consistency in production and lifestyle between urban and rural areas. Specifically, urban and rural residents can earn the same income, consume the same products, and enjoy the same public services.

Based on the analysis, this paper subdivides the four primary indexes into several secondary indexes and selects some appropriate indicators for each secondary index (Table 1). 
Table 1. Indicators and their weights of urbanization quality.

\begin{tabular}{|c|c|c|c|}
\hline Primary Indexes & Secondary Indexes & Indicators & Weight \\
\hline \multirow{23}{*}{$\begin{array}{l}\text { The Quality of Urban } \\
\text { Development }\end{array}$} & \multirow{6}{*}{ Economic Development } & real per capita GDP (yuan) & 0.0116 \\
\hline & & per capita government revenue (yuan) & 0.0140 \\
\hline & & the level of urbanization $(\%)$ & 0.0196 \\
\hline & & the secondary industry added value ( $\%$ of GDP) & 0.0134 \\
\hline & & the tertiary industry added value (\% of GDP) & 0.0152 \\
\hline & & GDP growth rate $(\%)$ & 0.0184 \\
\hline & \multirow{6}{*}{ Social Development } & social security expenditure (\% of GDP) & 0.0155 \\
\hline & & hospital beds per 10,000 population (bed) & 0.0092 \\
\hline & & physicians per 10,000 population (person) & 0.0137 \\
\hline & & books per 100 population (copies) & 0.0059 \\
\hline & & college students per 100,000 population (person) & 0.0118 \\
\hline & & unemployment rate $(\%)$ & 0.0236 \\
\hline & \multirow{3}{*}{ Ecological Environment } & $\mathrm{SO}_{2}$ emissions per $10,000 \mathrm{GDP}(\mathrm{kg})$ & 0.0369 \\
\hline & & waste water discharge per 10,000 GDP (ton) & 0.0376 \\
\hline & & solid waste production per 10,000 industrial added value (ton) & 0.0380 \\
\hline & \multirow{5}{*}{ Living Standard } & urban per capita disposable income (yuan) & 0.0147 \\
\hline & & per capita household saving (yuan) & 0.0075 \\
\hline & & urban Engel coefficient $(\%)$ & 0.0142 \\
\hline & & urban population density (person/sq. km) & 0.0255 \\
\hline & & per capita electricity consumption (Kwh/person) & 0.0075 \\
\hline & \multirow{3}{*}{ Infrastructure } & per capita area of paved road in city (sq.m.) & 0.0179 \\
\hline & & buses per 10000 population (unit) & 0.0157 \\
\hline & & per capita area of green land (sq. m) & 0.0124 \\
\hline \multirow{10}{*}{$\begin{array}{l}\text { The Sustainability of } \\
\text { Urban Development }\end{array}$} & \multirow{4}{*}{ Economic Sustainability } & total investment in fixed assets (\% of GDP) & 0.0475 \\
\hline & & total retail sales of consumer goods ( $\%$ of GDP) & 0.0209 \\
\hline & & total value of import and export (\% of GDP) & 0.0153 \\
\hline & & transaction value in technical markets (\% of GDP) & 0.0137 \\
\hline & \multirow{2}{*}{ Social Sustainability } & social burden coefficient (\%) & 0.0357 \\
\hline & & science, education, culture and health expenditure (\% of GDP) & 0.0161 \\
\hline & Environmental & environmental protection expenditure (\% of GDP) & 0.0209 \\
\hline & \multirow{3}{*}{ Sustainability } & environmental system staff (\% of total population) & 0.0189 \\
\hline & & $\begin{array}{l}\text { industrial pollution control investment (\% of industrial added } \\
\text { value) }\end{array}$ & 0.0198 \\
\hline & & green covered area ( $\%$ of completed area) & 0.0112 \\
\hline \multirow{7}{*}{$\begin{array}{l}\text { The Efficiency of } \\
\text { Urbanization }\end{array}$} & Labor Productivity & per employee GDP (yuan) & 0.0130 \\
\hline & Capital Productivity & ICOR $(\%)$ & 0.0334 \\
\hline & \multirow{2}{*}{ Land Use Efficiency } & GDP per sq. km (10,000 yuan) & 0.0125 \\
\hline & & employment per sq. km (person) & 0.0176 \\
\hline & \multirow{3}{*}{ Resource Efficiency } & energy consumption per 10,000 GDP (tons) of SCE) & 0.0324 \\
\hline & & electricity consumption per 10,000 GDP (Kwh) & 0.0343 \\
\hline & & water supply per 10,000 GDP (tons) & 0.0368 \\
\hline \multirow{6}{*}{$\begin{array}{l}\text { The Urban-Rural } \\
\text { Integration }\end{array}$} & \multirow{2}{*}{$\begin{array}{l}\text { Income Consumption } \\
\text { Integration }\end{array}$} & per capita income gap & 0.0407 \\
\hline & & per capita consumption gap & 0.0395 \\
\hline & \multirow{4}{*}{$\begin{array}{l}\text { Public Service } \\
\text { Integration }\end{array}$} & primary schools' student-teacher ratio gap & 0.0372 \\
\hline & & secondary schools' student-teacher ratio gap & 0.0234 \\
\hline & & per 10,000 population medical personnel gap & 0.0260 \\
\hline & & per 10,000 population hospital beds gap & 0.0331 \\
\hline
\end{tabular}

Note: (i) The last column shows the weight of each indicator that calculated in the section 4. (ii) ICOR (incremental capital output ratio) is a metric that assesses the marginal amount of investment capital necessary for an entity to generate the next unit of production. Overall, a higher ICOR value is not preferred because it indicates that the entity's production is inefficient. ICOR is calculated as: ICOR $=\frac{\text { Annual Investment }}{\text { Annual Increase in GDP }}$. (iii) Urban rural income (consumption) gap is the ratio of rural per capita income (consumption) to urban per capita income. (iv) Due to the data limitations, we could not include all indicators that should have been included.

\section{Materials and Methods}

\subsection{Sampling Design}

This paper collects a provincial panel dataset in China from 1985 to 2015 (1985, 1990, 1995, 2000, and annually from 2005 to 2015). It contains data for all indicators collected in 30 provinces and the national aggregate. We excluded four regions (Hong Kong, Macao, Taiwan, and Tibet) for lack of data. This dataset is collected from China Statistical Yearbooks, China City Statistical Yearbook, China 
Energy Statistical Yearbook, China Environmental Yearbook, and China Rural Statistical Yearbook 1986-2016. By using this panel data, the study can demonstrate evolutionary trends and spatial characteristics of urbanization quality, which differs from previous studies based only on cross-sectional data.

\subsection{Methods}

\subsubsection{Deviation Maximization Method}

This paper uses the Deviation Maximization Method developed by Guo [40]. The advantage of this method is that all the weights are calculated from the characteristics by using all the values both across all regions and across all time periods. Thus, the weights objectively reflect both the geographical and evolutional differences of the data, and avoiding any human subjective preferences. Moreover, it ensures all weights will stay the same over time.

The Urbanization Quality Index (UQI) is calculated by the following formula:

$$
y_{i}\left(t_{k}\right)=\sum_{j=1}^{m} \omega_{j} x_{i j}\left(t_{k}\right),(i=1,2, \ldots, 3 ; j=1,2, \ldots, m ; k=1,2, \ldots, T .) .
$$

In this paper, region $i$ includes 30 provinces and the national aggregate; $j$ represents the 46 indicators; year $t_{k}$ includes 1985, 1990, 1995, 2000, and annually from 2005 to 2015; $\omega_{j}$ is factor weight to be calculated in the procedure below; $x_{i j}\left(t_{k}\right)$ is the value of indicator $j$ in region $i$ in year $t_{k}$, $y_{i}\left(t_{k}\right)$ is the composite index of urbanization quality for region $i$ in year $t_{k}$.

Step 1 is to normalize the indicators into comparable units using Min-Max scaling. The Min-Max scaling maximizes the overall difference among the assessed indicators and is the most suitable dimensionless method for Deviation Maximization Method [41]. If index value $x_{i j}$ is positive, namely, higher value is preferred, such as real per capita GDP and GDP growth rate, then it is normalized as $x_{i j}^{\prime}=\frac{x_{i j}-m_{j}}{M_{j}-m_{j}}$. If index value $x_{i j}$ is negative, namely, a smaller value is preferred, such as unemployment rate and $\mathrm{SO}_{2}$ emissions per 10,000 GDP, then it is normalized as $x_{i j}^{\prime}=\frac{M_{j}-x_{i j}}{M_{j}-m_{j}}$. In which, $m_{j}=\min \left\{x_{i j}\right\}, M_{j}=\max \left\{x_{i j}\right\}$. After this normalization, all $x_{i j}^{\prime}$ are between 0 and 1 and represent the difference from the most desirable value possible.

Step 2 is to calculate the weight for each indicator $\omega_{j}$. The principle of determining the weight factor $\omega_{j}$ is to maximize the difference among assessed regions as far as possible, which is to maximize $e^{2}=\sum_{k=1}^{T} \sum_{i=1}^{n}\left(y_{i}\left(t_{k}\right)-\bar{y}\right)^{2}$, where $\bar{y}=\frac{1}{T} \sum_{k=1}^{T}\left(\frac{1}{n} \sum_{i=1}^{n} \sum_{j=1}^{m} \omega_{j} x_{i j}\left(t_{k}\right)\right)=0$. As a result,

$$
e^{2}=\sum_{k=1}^{T} \sum_{i=1}^{n}\left(y_{i}\left(t_{k}\right)\right)^{2}=\sum_{k=1}^{T}\left[W^{T} H_{K} W\right]=W^{T} \sum_{k=1}^{T} H_{K} W=W^{T} H W
$$

in which, $W=\left(\omega_{1}, \omega_{2}, \ldots, \omega_{m}\right)^{T}, H=\sum_{k=1}^{T} H_{k}$ is a $m \times m$ symmetric matrix, $H_{k}=X_{k}^{T} X_{k}$, $(k=1,2, \ldots, T)$ and $X_{k}=\left[\begin{array}{ccc}x_{11}\left(t_{k}\right) & \ldots & x_{1 m}\left(t_{k}\right) \\ \vdots & \ddots & \vdots \\ x_{n 1}\left(t_{k}\right) & \ldots & x_{n m}\left(t_{k}\right)\end{array}\right]$. It can be proved that if $W W^{T}=1, \mathrm{e}^{2}$ reaches maximum when $W$ is the eigenvector corresponding to the largest eigenvalue of matrix $H$.

Step 3 is to substitute the $\omega_{j}$ calculated in Step 2 into Equation (1) to calculate the UQI $y_{i}\left(t_{k}\right)$ for region $i$ in year $t_{k}$.

\subsubsection{Exploratory Spatial Data Analysis}

Exploratory Spatial Data Analysis includes visual and quantitative methods to summarize a variable's spatial properties [42]. Moran's I and LISA are two key indexes to perform this analysis. The former is used for employing global spatial autocorrelation from the whole study area; the latter is used for assessing local spatial autocorrelation from a local level. 
Moran's I is given below:

$$
I=\frac{n \sum_{i=1}^{n} \sum_{j=1}^{n} \mu_{i j}\left(x_{i}-\bar{x}\right)\left(x_{j}-\bar{x}\right)}{\left(\sum_{i=1}^{n} \sum_{j=1}^{n} \mu_{i j}\right) \sum_{i=1}^{n}\left(x_{i}-\bar{x}\right)^{2}}
$$

in which $I$ is a global spatial correlation coefficient. It ranges from -1 to +1 , with +1 indicating a strong positive spatial autocorrelation, 0 indicating a random or no correlation, and -1 indicating a strong negative spatial autocorrelation. $n=30$ is the number of study regions. $\mu_{i j}$ is the matrix of space weights; $x_{i}$ is the UQI in region $i$; and $\bar{x}$ is the average UQI in all regions.

The local value of a LISA is computed as follows:

$$
I_{i}=\frac{n^{2}}{\sum_{i} \sum_{j} \mu_{i j}} \times \frac{\left(x_{i}-\bar{x}\right) \sum_{j} \mu_{i j}\left(x_{j}-\bar{x}\right)}{\sum_{j}\left(x_{i}-\bar{x}\right)^{2}}
$$

For each location, the LISA values illustrate the correlation among adjacent regions and the significance of this correlation. There are five possible correlations: High-High reflects locations with high values among high-value neighbors; Low-Low reflects locations with low values among low-value neighbors; Low-High reflects locations with low values among high-value neighbors; High-Low reflects locations with high values among high-value neighbors; Not significant reflects no correlation among adjacent regions.

\section{Results and Implications}

This paper uses Matlab2015b to process data and calculate the weight of each indicator (Table 1), to obtain the Urbanization Quality Index (UQI) of 30 provinces and the national average.

\subsection{The Trend of Urbanization Quality}

As shown in Figure 1, the national UQI rises from 0.54 to 0.66 , which means the urbanization quality in China has slowly improved from 1985 to 2015. The gap of urbanization quality among the 30 provinces has narrowed. This is because the national UQI was ranked 9th among the 30 provinces in 1985, but dropped to 17 th in 2015. This shows that the more urbanized regions no longer significantly lift the national average so that the national average is much more toward the median.

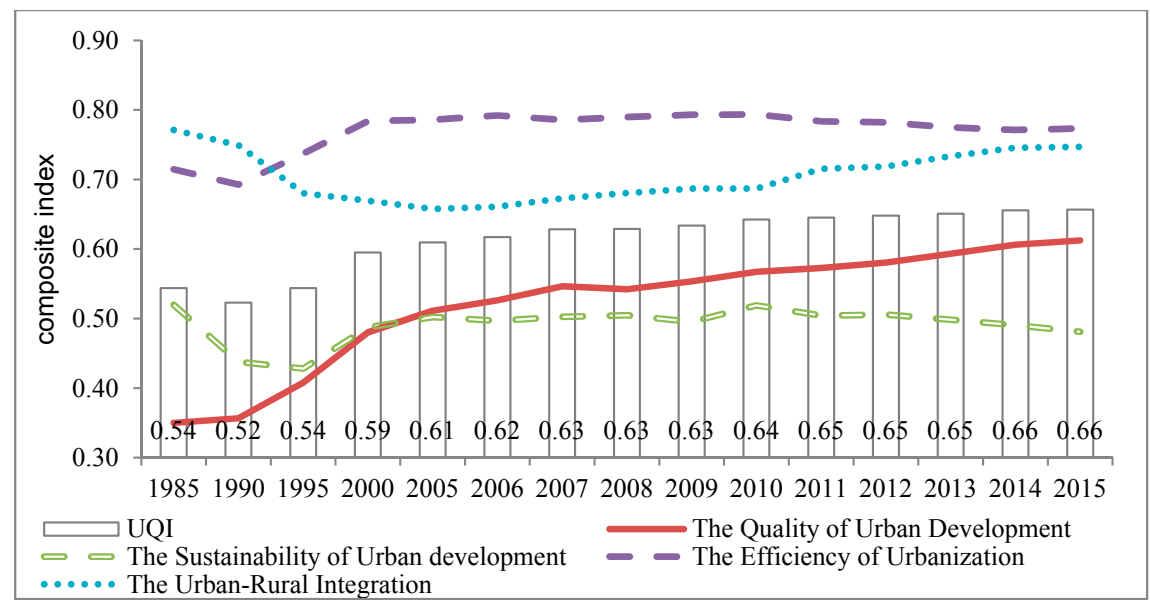

Figure 1. The composite index of urbanization quality in China from 1985 to 2015. Note: In order to show the graph clearly, the values of ecological environment and resource efficiency are reduced by 10 times; therefore, the data in the graphs can only reflect the trends and are not comparable in scale. 
When zooming in on the four aspects of urbanization quality individually (Figure 1), there are some more interesting findings.

First, the quality of urban development has a clear upward trend, indicating a good development in the cities. The reasons can be summarized as follows according to Figure 2a. Since China's economic reform, the urban infrastructure in China has improved dramatically, which creates a solid foundation for economic and social development and raises the living standard. However, there are also some hidden dangers to urban development. The slowdown of economic growth after 2008 indicates that China's economic development has entered a new period of sluggish growth. The challenge of China's economic development at this stage is to carry out economic reform, and upgrade the industrial structure [43]. There is great uncertainty about whether China will face prosperity from a successful transition or a downturn from a failed transition. In addition, the ecological environment improved slightly during the early period of economic reform, but has hardly improved since then. In recent years, all major cities in China have struggled with pollution. As China's Environmental Status Bulletin 2016 reports, $75.1 \%$ of cities did not meet the air quality guidelines in 2016. Therefore, it is an important and difficult task to improve the quality of the ecological environment in cities.

Second, the sustainability of urban development had ups and downs before 2010, but has declined ever since. As shown in Figure 2b, economic sustainability has always been declining, yet social and environmental sustainability have risen slowly. After these two forces played out, the overall sustainability of urban development declined. Although urbanization has developed rapidly since China's economic reform, it lacks sustainability. There may be two reasons. Firstly, China's economic development in the past relied, to a large extent, on large-scale investment, demographic dividends, and net export surpluses due to cost advantages; however, as the economic development entered a new stage, the advantages of promoting economic growth in the past were gradually lost. If there is not a new impetus, economic development will not be sustainable [44]. Secondly, with the improvement of living standards, people still place higher demands on public services, social security, and environmental quality although social and environmental sustainability has improved. In particular, the arrival of an aging society has posed unprecedented challenges to the existing social security system and the frequent haze has aroused the concern of the whole nation $[45,46]$. Therefore, it is imperative to enhance socially and environmentally sustainable development.

Third, the efficiency of urbanization has not changed significantly. It improved slightly before 2006 and then declined slowly. When zooming in on the four aspects shown in Figure 2c, the labor productivity has been continuously improving, the land use and resource efficiency has not changed much, and the capital productivity has deteriorated. The reason can be summarized as follows. The improvement of labor productivity in China may be closely related to two factors. The first is a widening income gap between urban and rural areas and a large amount of rural surplus labor moving to the cities, achieving the optimal allocation of labor resources [47]. The second is the popularization of compulsory education: the expansion of higher education has greatly improved the productivity of the labor force. According to China's statistics, the number of migrant workers increased from 19.12 million in 1978 to 286 million in 2017 [3], while the average schooling years increased from 7.1 years in 1987 to 10.6 years in 2015 and the number of college students per 100,000 population increased from 179 in 1987 to 2524 in 2015 [48]. Land use efficiency has always been at a low level, which is likely related to "land financing." According to the study, local governments intervene in the operation of the land market through differentiated land price policies for the purpose of achieving their GDP goals and increasing fiscal revenue, resulting in the over-supply of land [49]. The resource efficiency is affected by a number of complex factors, such as the industrial structure, technology, energy structure, input prices, investment, etc. In the past three decades, the improvement of technology and the increase of resource prices may improve the resource efficiency to a certain extent. However, China is still in the middle stages of industrialization. The energy-intensive industries that mainly consume steel, cement, and other basic raw materials account for a large proportion of the 
economy. The coal-based energy structure has not fundamentally changed [50]. All these may lead to low resource efficiency. As a result of interaction, the resource efficiency in China has been at a low level of stability. The main reason for the continuous decline in capital productivity may be excessive investment leading to diminishing returns of scale. According to international experience, investment accounts for an average of $20 \%$ to $30 \%$ of GDP in developing countries. However, investment has contributed an average of $38.3 \%$ of China's economic growth in the past four decades; this figure is as high as $51.9 \%$ after 2000 [51]. Such long-term and large-scale investment has caused management risk and inefficient allocation of capital [52].

Fourth, the urban-rural integration shows a trend of improvement after the deterioration of the first two decades- that is, the gap between urban and rural areas expanded before 2005 but narrowed after that. Specifically, as shown in Figure 2d, the income consumption gap between urban and rural areas first expanded and then narrowed. The public services gap began to shrink but has been expanding since 2011. In this regard, a reasonable explanation is the following. In the early days of economic reform, the government put forward an economic development policy that allowed some regions to get rich first and then help others get rich later. Under this policy, the government strongly supported the development of developed regions, and the city gained more opportunities. As a result, the gap between urban and rural areas started to widen. However, with the continuous development of the economy, policymakers realized that the widening urban-rural gap may cause social instability and unsustainable economic development. Therefore, the government has proposed a strategy of "coordinating urban and rural development" and has formulated a series of policies to promote rural development since 2002 [53]. The implementation of these policies has curbed the expansion of the urban-rural gap; after several years of adjustment, the urban-rural gap began to narrow and urban-rural integration gradually improved.

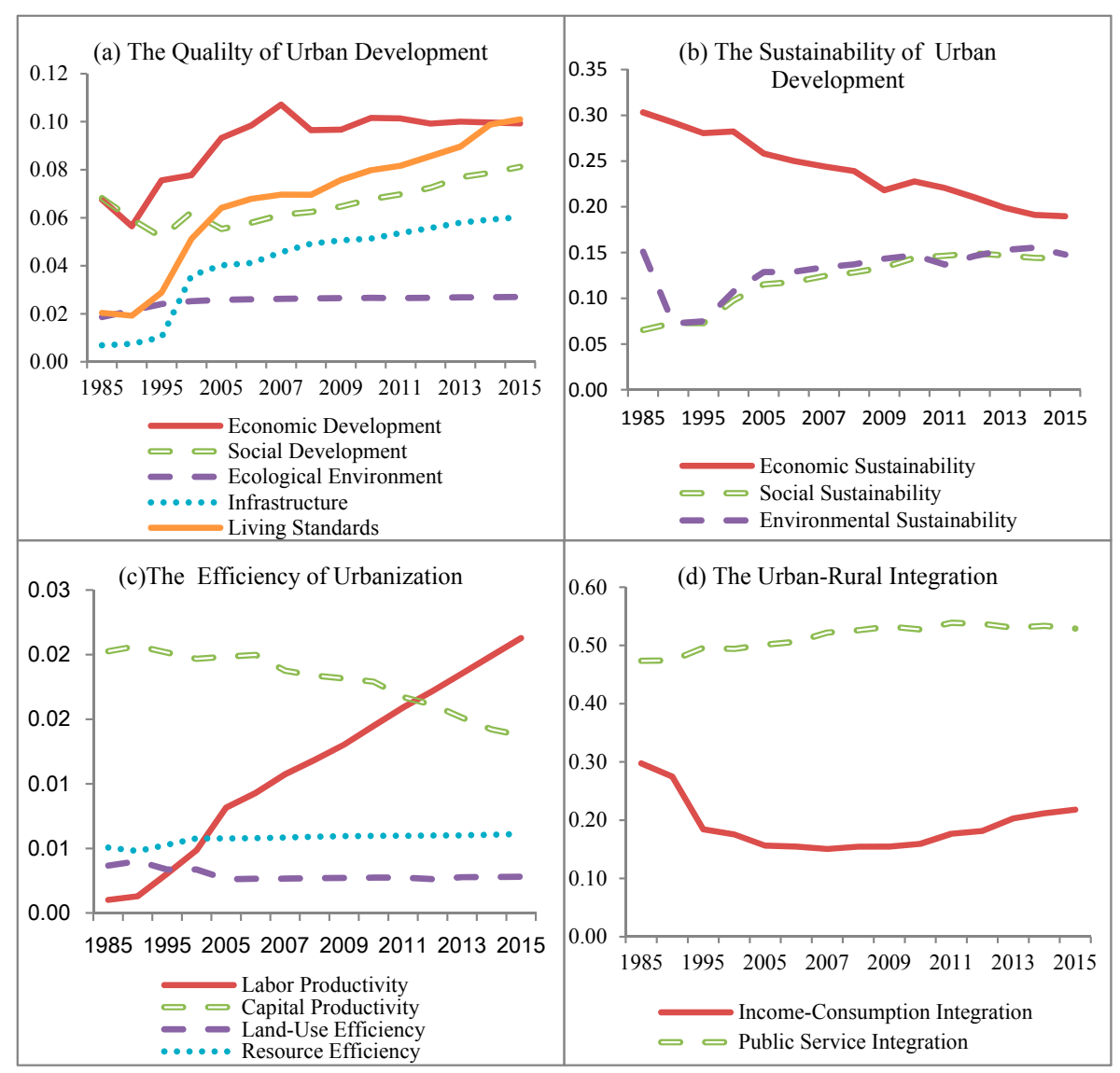

Figure 2. The secondary indexes of urbanization quality in China from 1985 to 2015. 


\subsection{The Spatial Difference of Urbanization Quality}

In order to characterize the distribution of urbanization quality, this paper divides urbanization quality into several categories. There has been no standard evaluation for urbanization quality. Therefore, this paper divides the urbanization quality into five categories according to the normal distribution rules and each level has an interval of 0.05 . Since the minimum and maximum UQI across regions is 0.40 and 0.81 , therefore the average of UQI is 0.605 . Suppose the medium quality category ranges from 0.58 to 0.63 , of which 0.605 is the average; we classify urbanization quality into five categories: low quality (<0.53), low to medium quality (0.53-0.58), medium quality (0.58-0.63), medium to high quality (0.63-0.68) and high quality (>0.68). By applying the results of four selected years 1985, 1995, 2005, and 2015 to ArcGIS, we obtain four spatial difference maps (Figure 3). The average and difference of UQI of 30 provinces and the nation average are shown in Table 2.

From an overall point of view, the urbanization quality in China's provinces has improved from 1985 to 2015, but there are also some differences between regions (Table 2 and Figure 3). In terms of the level of development, which is reflected by the average UQI, Beijing and Shanghai have the highest UQI, with an average UQI of 0.68 or above, which is in the high quality category; Ningxia and Guizhou have the lowest UQI, with an average UQI of below 0.53 , which is in the low quality category. In terms of speed of development, which is reflected in the difference of UQI, the five fastest developing regions are Beijing, Shandong, Tianjin, Sichuan, and Chongqing, yet the five slowest regions are Xinjiang, Qinghai, Ningxia, Yunnan and Anhui.

These results can be analyzed on the basis of geographic location. Beijing and Shanghai are China's political and economic centers, respectively. Shandong and Tianjin are important ports of entry. Sichuan and Chongqing are the hubs of science, technology, and trade in the southwest region. Due to the geographical and policy advantages, all these provinces have experienced balanced development in each dimension across our study period. As a consequence, urbanization results in higher quality of a faster speed. In contrast, Ningxia, Guizhou, Xinjiang, Qinghai, and Yunan are remote and have weaker economic foundations, backward infrastructure, and limited industrial development. All these regions have disadvantages in the four aspects of urbanization. Taking Xinjiang and Qinghai as examples, both show a trend of continuous declination in the efficiency of urbanization and the sustainability of urban development. In conclusion, the geographic location is an important factor affecting the quality of urbanization.

Table 2. The average and difference of UQI from 1985 to 2015.

\begin{tabular}{ccccccccc}
\hline Provinces & Avg. & Diff. & Provinces & Avg. & Diff. & Provinces & Avg. & Diff. \\
\hline Beijing & 0.72 & 0.21 & Heilongjiang & 0.62 & 0.16 & Shaanxi & 0.58 & 0.12 \\
Shanghai & 0.70 & 0.15 & Hubei & 0.62 & 0.12 & Chongqing & 0.58 & 0.17 \\
Tianjin & 0.67 & 0.18 & The Nation Average & 0.60 & 0.10 & Guangxi & 0.57 & 0.13 \\
Jiangsu & 0.66 & 0.15 & Hunan & 0.60 & 0.15 & Xinjiang & 0.56 & 0.02 \\
Zhejiang & 0.65 & 0.15 & Hebei & 0.60 & 0.15 & Yunnan & 0.56 & 0.10 \\
Guangdong & 0.65 & 0.17 & Inner Mongolia & 0.59 & 0.12 & Gansu & 0.54 & 0.16 \\
Shandong & 0.64 & 0.18 & Henan & 0.59 & 0.14 & Qinghai & 0.53 & 0.09 \\
Fujian & 0.63 & 0.14 & Jiangxi & 0.59 & 0.16 & Guizhou & 0.52 & 0.14 \\
Jilin & 0.62 & 0.13 & Sichuan & 0.59 & 0.18 & Ningxia & 0.5 & 0.09 \\
Hainan & 0.62 & 0.12 & Shanxi & 0.58 & 0.12 & & & \\
Liaoning & 0.62 & 0.12 & Anhui & 0.58 & 0.11 & & & \\
\hline
\end{tabular}



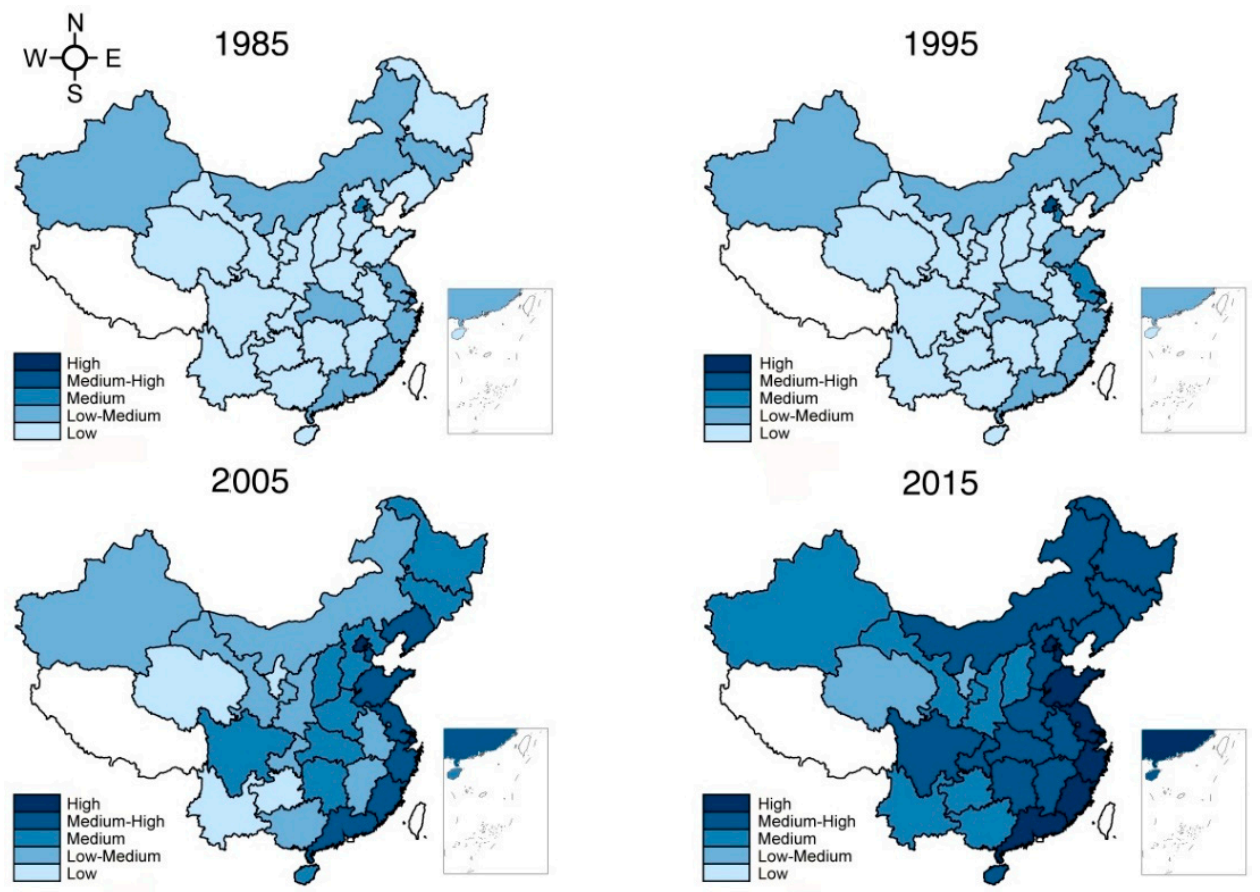

Figure 3. The spatial difference maps of urbanization quality in China from 1985 to 2015.

From a regional point of view, the urbanization quality in the eastern coastal areas is superior to that in the central and western regions. Chronologically speaking, from 1985 to 1995, only Beijing, Shanghai, Tianjin, and Jiangsu reached the medium to high quality category; the rest of the provinces were in the low to medium quality or below categories. The provinces in the low to medium quality category were mainly concentrated in the eastern coastal areas, such as Jilin, Liaoning, Heilongiiang, Zhejiang, Shandong, Fujian, and Guangdong, and the provinces in the low quality category were located in the central and western regions. In 2005, the number in the medium quality category and above provinces increased to eighteen as Tianjin, Liaoning, Jiangsu, Zhejiang, Fujian, Shandong, and Guangdong all reached the medium to high quality category; Beijing and Shanghai entered into the high quality category, while most central provinces were in the medium quality category and the western regions were in the low to medium quality category except Sichuan, which is medium quality. In 2015, among the eleven eastern provinces, eight reached the high quality category except for Hebei, Liaoning, and Hainan; among the eight central provinces, seven were in the medium to high quality category except for Shanxi, while the western provinces varied a lot, in which Inner Mongolia, Chongqing, and Sichuan were in the medium to high quality category, Qinghai and Ningxia were in the low to medium quality category and the rest of the provinces were in the medium quality category. In general, the spatial difference of urbanization quality is significant and shows a cluster distribution to a certain extent.

\subsection{The Spatial Association of Urbanization Quality}

\subsubsection{Global Spatial Autocorrelation Analysis of Urbanization Quality}

This paper uses GeoDa1.10 to calculate Moran's I in the selected years 1985, 1995, 2005, and 2015 to conduct the global spatial autocorrelation analysis. Table 3 shows the Moran's I of urbanization quality and its four aspects.

It is apparent that all Moran's I are positive and the Z scores are larger than the critical value (1.96) at the $95 \%$ confidence level, indicating that the urbanization quality in China has a positive global spatial autocorrelation every year, which means the urbanization quality in each province is affected by its neighbor provinces. The Moran's I of urbanization quality was the largest in 2005, indicating the strongest spatial autocorrelation, while it decreased slightly in 2015. As for the four aspects of 
urbanization quality, the Moran's I of urban-rural integration is generally larger than the other three aspects, which means urban-rural integration has the strongest spatial autocorrelation among the four aspects, yet the Moran's I of the sustainability of urban development is generally smaller than the other three aspects, which means it has the weakest spatial autocorrelation among the four aspects.

Table 3. The Moran's I of urbanization quality from 1985 to 2015.

\begin{tabular}{|c|c|c|c|c|c|c|c|c|c|c|c|c|}
\hline & \multicolumn{3}{|c|}{1985} & \multicolumn{3}{|c|}{1995} & \multicolumn{3}{|c|}{2005} & \multicolumn{3}{|c|}{2015} \\
\hline & Moran's I & $\mathrm{Z}$ & $\mathrm{P}$ & Moran's I & Z & $\mathrm{P}$ & Moran's I & $\mathrm{Z}$ & $\mathrm{P}$ & Moran's I & Z & $\mathrm{P}$ \\
\hline $\begin{array}{c}\text { the urbanization } \\
\text { quality }\end{array}$ & 0.269 & 2.57 & 0.005 & 0.432 & 3.93 & 0.002 & 0.498 & 4.44 & 0.001 & 0.453 & 4.04 & 0.002 \\
\hline $\begin{array}{c}\text { the quality of urban } \\
\text { development }\end{array}$ & 0.353 & 3.27 & 0.001 & 0.364 & 3.45 & 0.002 & 0.403 & 3.74 & 0.001 & 0.321 & 3.00 & 0.006 \\
\hline $\begin{array}{l}\text { the sustainability of } \\
\text { urban development }\end{array}$ & 0.123 & 1.43 & 0.079 & 0.258 & 2.49 & 0.014 & 0.277 & 2.55 & 0.011 & 0.200 & 2.08 & 0.025 \\
\hline $\begin{array}{l}\text { efficiency of } \\
\text { urbanization }\end{array}$ & 0.396 & 3.71 & 0.003 & 0.307 & 2.95 & 0.006 & 0.243 & 2.59 & 0.014 & 0.363 & 3.38 & 0.002 \\
\hline $\begin{array}{l}\text { urban-rural } \\
\text { integration }\end{array}$ & 0.124 & 1.41 & 0.084 & 0.453 & 3.89 & 0.001 & 0.453 & 4.07 & 0.001 & 0.514 & 4.67 & 0.001 \\
\hline
\end{tabular}

\subsubsection{Local Spatial Autocorrelation Analysis of Urbanization Quality}

Moran's I examines the global spatial autocorrelation of urbanization quality from the whole study area, but fails to reveal the spatial heterogeneity at a local level. Therefore, LISA is used to assess the local clustering of urbanization quality. Figure 4 is LISA cluster maps for urbanization quality at the $95 \%$ confidence level in the selected years 1985, 1995, 2005, and 2015. Several conclusions can be drawn from these maps.

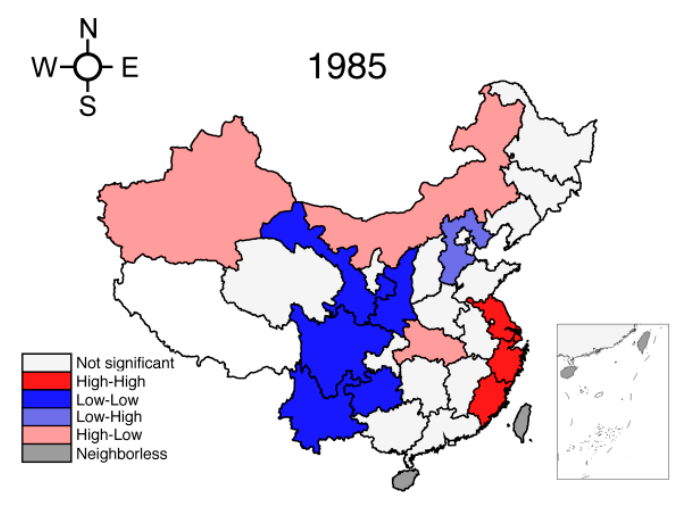

2005

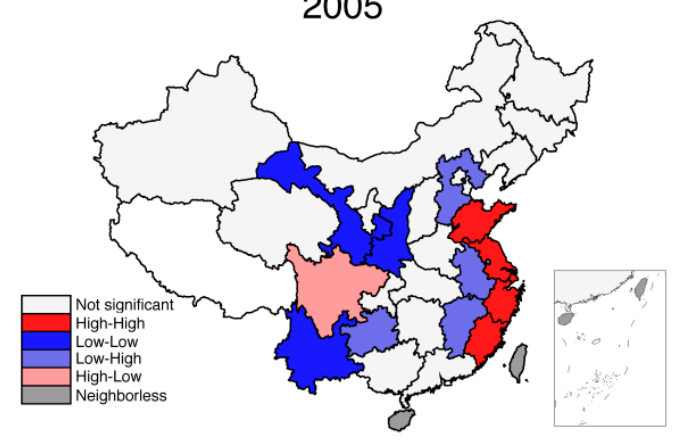

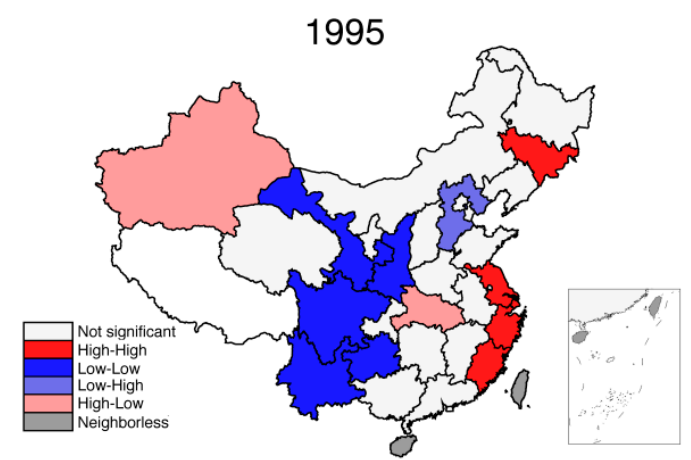

2015

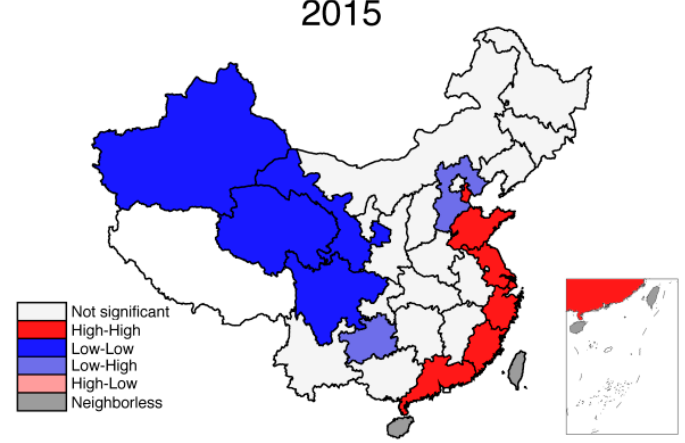

Figure 4. LISA cluster maps for urbanization quality in China from 1985 to 2015.

From the point of view of historical evolution, $50 \%$ of the provinces have an unchanged spatial correlation during the study period, indicating that most provinces have a relatively stable spatial correlation in urbanization quality, among which Shanghai, Jiangsu, Zhejiang, and Fujian are always 
in the High-High cluster areas (i.e., high-quality development has a positive spillover effect on its neighbor's urbanization process), while Gansu is always in the Low-Low cluster areas (i.e., low-quality development has a negative impact on its neighbor's urbanization process).

From the point of view of spatial distribution, the High-High cluster areas are mainly concentrated in the eastern coastal areas, and its number increased from four provinces in 1985 to seven in 2015, forming a linkage area with obvious spillover effects. Due to the advantages for resources, transportation, the environment, and preferential policies, the urbanization quality in these areas is significantly higher than that of the central and western regions. These areas have become important growth poles that stimulate the progress of urbanization in the surrounding areas.

The Low-Low cluster areas are mainly distributed in the western regions. Shaanxi and Yunnan escaped the Low-Low cluster in 2015, but Xinjiang and Qinghai fell into the Low-Low cluster. The main reason may be that the formers vigorously develop cultural tourism to promote the development of cities by virtue of the advantages of natural resources. However, the latter, due to their geographical disadvantages and the failure to fully exploit and utilize regional resources, have had a relatively backward development.

The Low-High cluster areas are mainly located in Hebei, Anhui, Jiangxi, and Guizhou. Hebei province is lower in urbanization quality compared with its surrounding regions of Beijing and Tianjin. The main reason is that Beijing and Tianjin are superior in terms of capital, resources, and policies since Beijing is the capital of the nation and Tianjin is the economic center of Bohai Bay Rim. Hebei province has always played a supporting role by providing capital, labor, and other resources to the other two areas, resulting in "siphon effects" in regional development [54]. For Anhui and Jiangxi, they showed a Low-High cluster characteristic in 2005, indicating that the eastern coastal areas have not only failed to promote urbanization in their neighboring inland provinces, but may even have squeezed their development opportunities to some extent. Guizhou, relative to its neighboring provinces, is disadvantaged in terms of resources and development opportunities, thus the urbanization process is slow.

The High-Low cluster areas include Xinjiang, Hubei, and Sichuan. Xinjiang, as a communications center of the ancient and modern Silk Road, relying on its mineral resources, agriculture, and geographical advantages, was significantly more advanced in urban development than the surrounding areas before 2005; however, it was sluggish after that and fell to the same level as the surrounding area. Hubei, located in central China, relying on the geographical advantages and the relatively developed industrial foundation as well as abundant human resources, is superior to the surrounding areas in terms of urbanization quality. Sichuan transferred from the Low-Low cluster to the High-Low cluster for two reasons. In addition to the geographical advantages and abundant natural resources, the successful transfer may be more due to policies. In 1993, Chengdu, the capital of Sichuan province, was established as southwest China's science and technology, commerce, and financial center, and its transportation and communication hub. Subsequently, Sichuan has been the first choice for where to build a reform pilot area for China's Western Development Campaign since 1999. In addition, Sichuan is embracing unprecedented new opportunities for encountering with the policies of the Belt and Road and Yangtze River Economic Belt. The superposition of various policies and opportunities promoted the improvement of the urbanization quality in Sichuan.

\section{Conclusions}

In consideration of the inconsistency between China's current officially announced level of urbanization and the challenges to achieve and sustain actual urbanization quality, this paper constructs a four-dimensional Urbanization Quality Index, which includes the quality of urban development, the sustainability of urban development, the efficiency of urbanization, and the urban-rural integration to analyze the urbanization quality in China from 1985 to 2015. The paper first uses the Deviation Maximization Method to derive weights for a comprehensive assessment of the urbanization quality and then reveals its spatial association by the Exploratory Spatial Data Analysis. 
The main findings are as follows. First, according to the analysis of spatial differences based on the composite index (UQI), this paper concludes that the urbanization quality in China has gradually increased over time, but there have been significant differences between regions-that is, the urbanization quality in the eastern coastal areas was superior to that in the central and western regions. The geographic location is an important factor that affects the urbanization quality. Second, according to the analysis of the trends based on the secondary indexes, this paper draws on the four aspects of urbanization quality: (i) the quality of urban development has steadily increased, but two of its secondary indexes, economic development and ecological environment, need to be further improved; (ii) the sustainability of urban development has shown a downward trend in recent years due to a continued decline in economic sustainability; (iii) the efficiency of urbanization has declined slightly due to capital, land use and resource efficiency constraints; (iv) the urban-rural integration deteriorated in the early years, but then improved over time because policies to narrow the gap between urban and rural areas were implemented well. Third, according to the analysis of spatial association based on the composite index (UQI), this paper found that the urbanization quality among the 30 provinces has a significant positive global spatial autocorrelation. However the local spatial autocorrelation varies from eastern to western, that is, the High-High cluster areas in the eastern coastal areas enlarged over time, while the Low-Low cluster areas in the western regions experienced dynamic change; the Low-High cluster areas were mainly located in the Hebei, Anhui, Jiangxi, and Guizhou and the High-Low cluster areas were in Xinjiang, Hubei, and Sichuan.

Based on these findings, this paper concludes with policy recommendations for improving urbanization quality in China. First, since urbanization is a complex process involving population, economics, social issues, culture, environment, geographical development, etc., all these aspects should be taken into consideration when improving the urbanization quality. According to our research, the urbanization quality in China improved slowly due to the emphasis on the urban economic development and infrastructure, but ignored other aspects, such as social issues, environmental concerns, energy use and capital efficiency, urban-rural integration, and sustainability. Consequentially, these ignored aspects dragged down the overall improvement of the urbanization quality. Thus, policy makers should make it clear that urbanization involves not only economic development but also the other important aspects mentioned above. During the process of urbanization, people should be placed at the center, and the social problems related to them should be solved preferentially. The government should promote the social integration of migrant workers by carrying out a series of reforms on household registration, land transfer, social security, and other effective systems, and modernize the lifestyle of migrant workers through improving public services. In this way, migrant workers will benefit from complete urbanization. Moreover, the efficiency and sustainability of urbanization should be given more attention. The government should improve the efficiency of capital, land, and energy utilization through technological and institutional innovations and cut down on waste and pollution through industrial structural upgrading. Furthermore, the urban-rural integration should be emphasized. The government should guide the investment transfer to rural infrastructure and public services, lay out transportation networks between city and country, and optimize the allocation of industries and resources between urban and rural areas to achieve urban-rural integration.

Second, due to the obvious regional differences in the urbanization quality, each region should formulate a differentiated urbanization strategy based on its own characteristics. According to the results, the spatial difference of urbanization quality is largely determined by the natural resources endowments and policies. Therefore, each region should fully tap into its own advantages and adapt to local conditions. Specifically, eastern regions were the first experimental areas of economic reform by virtue of their advantageous location. The export-oriented development model has promoted the growth of a large number of labor-intensive enterprises and absorbed the rural surplus labor force to the maximum extent. Next, urbanization should focus on industrial structural upgrading. By building green cities, smart cities, or compact cities [20], the eastern regions will gradually form a sustainable urban circle with obvious advantages and a strong spatial correlation. The central regions 
have advantages in terms of transportation and resources, as they are a junction that connects east and west and south and north, which is an important driving force for their urbanization. The rich mineral resources and grain output have also laid a solid foundation for urbanization. Afterward, the foci of urbanization should be to scientifically guide the return of migrant workers, expand the existing urban agglomeration, and increase the radiation effect of the big cities in the region. However, the western regions lack natural resources and the internal motivation of urbanization. The policy factor is the driving force of urbanization. Therefore, the western regions should seize the opportunity, exploit the comparative advantages of labor and capital, and develop characteristic agriculture, tourism, labor-intensive light industries, and service industries that are compatible with the local resources and environment, to gradually narrow the gap with the central and eastern regions.

Third, for the evident spatial correlation of the urbanization quality, the promotion of urbanization quality should focus on the synergy effect between regions. Based on the results, the urbanization quality not only has a significant global spatial autocorrelation, but also forms four types of local clusters. In reality, China has currently formed an urban development pattern dominated by the urban agglomeration of the Yangtze River Delta, the Pearl River Delta, Beijing-Tianjin-Hebei, the middle reaches of the Yangtze River, and Chengdu-Chongqing. Therefore, the synergy effect between the regions is not only supported by theory, but also rooted in practice. In terms of specific policies, the top-level design should be given the first priority. The government should draw up regional long-term development strategies based on location characteristics and resource endowments to form an urban spatial structure with complementary functions and regional linkage. Moreover, a common goal for regional development is important. By setting a common goal, the regions can systematically deal with the problems of regional development imbalance, resource constraints, etc. Finally, good opportunities can multiply the synergy effect. China is conducting the three strategies of One Belt and One Road, the coordinated development of Beijing-Tianjin-Hebei, and the Yangtze River Economic Belt. The grand strategies will form a regional development pattern: the east leading, the central rising, the northeast revitalizing, and the west developing. If the government seizes these opportunities, urbanization will benefit from the synergy effect.

Supplementary Materials: The following are available online at http:/ /www.mdpi.com/2071-1050/10/8/2953/ s1.

Author Contributions: Conceptualization, Y.X. and X.W.; Methodology, Y.X. and Y.S.; Software, Y.X.; Validation, Y.X., Y.S. and X.W.; Formal Analysis, Y.X.; Data Curation, Y.X.; Writing-Original Draft Preparation, Y.X.; Writing-Review \& Editing, Y.X.; Visualization, Y.X., Y.S. and X.W.; Supervision, Y.S.; Project Administration, Y.S.; Funding Acquisition, Y.X.

Funding: This research was funded by the China Scholarship Council (Grant No. 201606270046).

Acknowledgments: We are thankful for the translation suggestions from Lauren Shultz and Mary Drummond at UNC-CH and Sameen at Wuhan University. We are thankful for the suggestions and efforts from the reviewers and editors.

Conflicts of Interest: The authors declare no conflict of interest.

\section{References}

1. United Nations; DESA. World Urbanization Prospects: The 2018 Revision; UN Department of Public Information: New York, NY, USA, 2018; pp. 1-3.

2. Yang, X.J. China's Rapid Urbanization. Science 2013, 342, 310. [CrossRef] [PubMed]

3. National Bureau of Statistics of China. China Statistical Yearbook 1979. 2018. Available online: http: / / www.stats.gov.cn/tjsj/ndsj/ (accessed on 26 June 2018).

4. United Nations, Department of Economic and Social Affairs. World Urbanization Prospects: 2018 Revision. Available online: https: / / esa.un.org/unpd/wup/ (accessed on 26 June 2018).

5. Bai, X.; Shi, P.; Liu, Y. Realizing China's Urban Dream. Nature 2014, 509, 158-160. [CrossRef] [PubMed]

6. David, S. Building the (China) Dream. In The China Reader: Rising Power, 6th ed.; Oxford University Press: Oxford, UK, 2016; pp. 210-213. 
7. Urdal, H.; Buhaug, H. An Urbanization Bomb? Population Growth and Social Disorder in Cities. Glob. Environ. Chang. 2013, 23, 1-10.

8. Shin, H.B. Geography: Rethinking the 'Urban' and 'Urbanization'. In Defining the Urban: Interdisciplinary and Professional Perspectives; Iossifova, D., Doll, C., Gasparatos, A., Eds.; Routledge: London, UK, 2017; pp. $27-39$.

9. Chaolin, G.; Liya, W.; Cook, I.G. Progress in Research on Chinese Urbanization. Front. Archit. Res. 2012, 1, 101-149. [CrossRef]

10. Friedmann, J. Four Theses in the Study of China's Urbanization. Int. J. Urban Reg. Res. 2006, 30, 440-451. [CrossRef]

11. McGranahan, G.; Satterthwaite, D. Urbanization Concepts and Trends; IIED: London, UK, 2014.

12. Ye, Y.M. Approach on China's Urbanization Quality. China Soft Sci. 2001, 7, 27-31.

13. The National Urban Survey Head Team, Research Group of Urban Survey Team in Fujian Province. Construction and Application of China's Urbanization Quality Assessment System. Stat. Res. 2005, 7, 15-19.

14. Li, M.Q.; Lang, X.B. The Connotation of Urbanization Quality and the Construction of its Assessment Index System. China Soft Sci. 2010, 46, 182-186.

15. Fang, C.L.; Wang, D.L. Comprehensive Measures and Improvement of Chinese Urbanization Development Quality. Geogr. Res. 2011, 30, 1931-1946.

16. Bao, Y.; Chen, Q. The Evolution of Quality Concept and the Quality of Urban Development. J. Tongji Univ. 2009, 6, 46-52.

17. Pan, J. Harmonious Urbanization-China's Environmental Governing and Ecological Civilization; Springer: Berlin/Heidelberg, Germany, 2016; pp. 75-105.

18. Caprotti, F. Critical Research on Eco-cities? A Walk through the Sino-Singapore Tianjin Eco-City, China. Cities 2014, 36, 10-17. [CrossRef]

19. Urban 21 Conference. Sustainable Cities: Environmentally Sustainable Urban Development. Available online: https://www.sida.se/contentassets/4ee300f60c6c4f9fa52a27426f2be13a/sustainableurban-development-and-environment_1641.pdf (accessed on 26 June 2018).

20. Artmann, M.; Kohler, M.; Meinel, G.; Jing, G.; Ioja, I.C. How Smart Growth and Green Infrastructure Can Mutually Support Each Other-A Conceptual Framework for Compact and Green Cities. Ecol. Indic. Stage Publ. 2018, in press. [CrossRef]

21. Bakıc1, T.; Almirall, E.; Wareham, J. A Smart City Initiative: the Case of Barcelona. J. Knowl. Econ. 2013, 4, 135-148. [CrossRef]

22. Chan, K.W. Fundamentals of China's Urbanization and Policy. China Rev. 2010, 10, 63-93.

23. Chan, K.W. The Household Registration System and Migrant Labor in China: Notes on a Debate. Popul Dev. Rev. 2010, 36, 357-364. [CrossRef] [PubMed]

24. Wang, G.X. The Basic Theory of Urbanization and Problems and Countermeasures of China's Urbanization. Popul. Res. 2013, 37, 43-51.

25. Qian, J.; Peng, Y.; Luo, C.; Wu, C.; Du, Q. Urban Land Expansion and Sustainable Land Use Policy in Shenzhen: A Case Study of China's Rapid Urbanization. Sustainability 2015, 8, 16. [CrossRef]

26. Huang, D.; Chan, R.C.K. On 'Land Finance' in Urban China: Theory and Practice. Habitat. Int. 2018, 75, 96-104. [CrossRef]

27. Zhang, L.; Zhao, S.X. Reinterpretation of China's Under-urbanization: A Systemic Perspective. Habitat. Int. 2003, 27, 459-483. [CrossRef]

28. Hattori, K.; Kagaya, K.; Inanaga, S. The Regional Structure of Surrounding Areas of Tokyo. Geography 1960, 33, 495-514. [CrossRef]

29. Un-Habitat. "Epilogue, the City Development Index (CDI)" (2000). Available online: http:/ /www.un.org/ ga/Istanbul+5/116.pdf (accessed on 4 July 2018).

30. Un-Habitat. Urban. Indicators Guideliners, United Nations Human Settlement Programe; United Nations Publications: New York, NY, USA, 2004; pp. 8-9.

31. Freeman, R.A. Report on the World Summit for Social Development. Buddh.-Christ. Stud. 1995, 14, $205-207$.

32. Węziak-Białowolska, D. Quality of Life in Cities-Empirical Evidence in Comparative European Perspective. Cities 2016, 58, 87-96. [CrossRef]

33. Biagi, B.; Ladu, M.G.; Meleddu, M. Urban Quality of Life and Capabilities: An Experimental Study. Ecol. Econ. 2018, 150, 137-152. [CrossRef] 
34. European Commission. Directorate-General for Regional and Urban Policy. In Quality of Life in European Cities 2015; Publications Office of the European Union: Luxembourg, 2016; pp. 5-7.

35. Yanitsky, O. The City and Ecology. Nauka Mostkow. 1987, 1, 167-174.

36. Childers, D.L.; Cadenasso, M.L.; Grove, J.M.; Marshall, V.; Mcgrath, B.; Pickett, S.T.A. An Ecology for Cities: A Transformational Nexus of Design and Ecology to Advance Climate Change Resilience and Urban Sustainability. Sustainability 2015, 7, 3774-3791. [CrossRef]

37. Un-Habitat. State of the World's Cities 2008-2009: Harmonious Cities; Earthscan: London, UK, 2008; pp. $29-43$.

38. Grădinaru, S.; Iojă, C.; Pătru-Stupariu, I.; Hersperger, A. Are Spatial Planning Objectives Reflected in the Evolution of Urban Landscape Patterns? A Framework for the Evaluation of Spatial Planning Outcomes. Sustainability 2017, 9, 1279. [CrossRef]

39. Jia, S.; Wang, C.; Li, Y.; Zhang, F.; Liu, W. The Urbanization Efficiency in Chengdu City: An Estimation Based on a Three-stage DEA Model. Phys. Chem. Earth 2017, 101, 59-69. [CrossRef]

40. Guo, Y. New Theory and Method of Dynamic Comprehensive Evaluation. J. Manag. Sci. 2002, 5, 50-54.

41. Guo, Y.J.; Ma, F.M.; Dong, Q.X. Analysis of Influence of Dimensionless Methods on Deviation Maximization Method. J. Manag. Sci. China 2011, 14, 19-28.

42. Anselin, L. Exploratory Spatial Data Analysis in a Geocomputational Environment Geocomputation, a Primer; Wiley: New York, NY, USA, 1998; pp. 77-94.

43. Zhang, J.; Otsuka, K.; Fu, X.; Yan, S. Introduction to Symposium: Structural Change, Industrial Upgrading and China's Economic Transformation. China Econ. Rev. 2017, 46, 1-2. [CrossRef]

44. Rajah, R.; Zhang, M.; Kong, X.X. Can China's Miraculous Economic Growth Continue? J. Contemp. Asia 2013, 43, 295-313.

45. Li, S.; Lin, S. Population Aging and China's Social Security Reforms. J. Policy Model. 2016, 38, 65-95. [CrossRef]

46. Lu, Y.; Wang, Y.; Zuo, J.; Jiang, H.; Huang, D.; Rameezdeen, R. Characteristics of Public Concern on Haze in China and Its Relationship with Air Quality in Urban Areas. Sci. Total Environ. 2018, 637-638, 1597-1606. [CrossRef] [PubMed]

47. Li, P.; Wang, C.; Zhang, X. Did City Cluster Development Help Improve Labor Productivity in China? J. Asia Pac. Econ. 2017, 22, 1-14. [CrossRef]

48. National Bureau of Statistics of China. 1\% National Population Sample Survey 1987. 2015. Available online: http:/ / www.stats.gov.cn/tjsj/pcsj/ (accessed on 26 June 2018).

49. Guo, S.; Liu, L.; Zhao, Y. The Business Cycle Implications of Land Financing in China. Econ. Model. 2015, 46, 225-237. [CrossRef]

50. Lo, K. A Critical Review of China's Rapidly Developing Renewable Energy and Energy Efficiency Policies. Renew. Sustain. Energy Rev. 2014, 29, 508-516. [CrossRef]

51. Lan, Y.P. Investment Drivers in China's Economic Growth. Int. Financ. 2008, 7, 64-68.

52. Pessarossi, P.; Weill, L. Do Capital Requirements Affect Cost Efficiency? Evidence from China. J. Financ. Stab. 2015, 19, 119-127. [CrossRef]

53. Ye, Y.; LeGates, R.; Qin, B. Coordinated Urban-rural Development Planning in China. J. Am. Plan. Assoc. 2013, 79, 125-137. [CrossRef]

54. Wen, K.; Zhu, E.J.; Ye, T.L. Blue Book of Beijing-Tianjin-Hebei 2014; Social Sciences Academic Press: Beijing, China, 2014; pp. 18-29.

(C) 2018 by the authors. Licensee MDPI, Basel, Switzerland. This article is an open access article distributed under the terms and conditions of the Creative Commons Attribution (CC BY) license (http://creativecommons.org/licenses/by/4.0/). 